\title{
O CORPO QUE (NÃO) VEMOS NOS Vê
}

\author{
EL CUERPO QUE (NO) VEMOS NOS VE
}

THE BODY THAT WE(DO NOT) SEE SEES US

\author{
Maria Thereza Veloso* \\ Universidade Regional Integrada do Alto Uruguai e das Missões
}

RESUMO: Sob a perspectiva da Análise do Discurso pêcheuxtiana e pretendendo-se um diálogo entre duas expressões distintas a literária e a fílmica - na perspectiva do corpo como conduto e expressão da constituição psicanalítica da linguagem, apresentamse aqui considerações acerca da análise interpretativa de Recortes Discursivos (RDs), retirados do romance Lavoura Arcaica, de Raduan Nassar, e sua adaptação/tradução para outra linguagem, mediante outro código, o imagético em movimento, de que resultou o filme homônimo, de Luis Fernando Carvalho. Para tanto, vê-se a linguagem como em estágio pré-discursivo, no centro do Nó Borromeano, no espaço intersticial dos círculos representativos da tríade lacaniana - do Real, do Simbólico e do Imaginário. Vê-se a linguagem igualmente como portadora de um caráter limítrofe entre o psíquico e o somático, ponto de partida para duas outras pulsões observadas por J. Lacan - a invocante e a escópica.

PALAVRAS-CHAVE: Linguagem literária. Linguagem fílmica. Corpo. Sentidos. Análise do discurso.

RESUMEN: Bajo la teoría del Análisis del Discurso pêcheuxtiano e intentando un diálogo entre dos expresiones distintas - la literaria y la fílmica - en la perspectiva del cuerpo como conductor y expresión de la construcción psicoanalítica del lenguaje, se presentan aquí aportes acerca de un análisis interpretativo de Recortes discursivos (RDs) - sacados de la novela Lavoura arcaica, de Raduan Nassar, y su adaptación/traducción a otro lenguaje y otro código, el de la imagen en movimiento, de que resultó la película homónima, de Luis Fernando Carvalho. Para eso, se ve el lenguaje como en un estadio prediscursivo, al centro del Nudo Borromeo, en el espacio intersticial formado por los tres anillos representativos de lo Real, de lo Imaginario y de lo Simbólico. Se presenta el lenguaje también como portador de un rasgo fronterizo entre lo psíquico y lo somático, punto de arranque para dos otras pulsiones observadas por Lacan - la invocadora y la escópica.

PALABRAS CLAVE: Lenguaje literario. Lenguaje fílmico. Cuerpo. Sentidos. Análisis del discurso.

ABSTRACT: Having as theoretical foundation Pêcheux's Discourse Analysis, and aiming to establish a dialogue between two different expressions - the literary and the filmic ones - in the perspective of the body as channel and expression of the psychoanalytic constitution of language, this article presents some considerations on Discursive Scraps (DSs) interpretative analysis. The analysis relies on Raduan Nassar's novel Lavoura Arcaica and on its adaptation/translation into other language and code - image in motion - from which resulted the homonymous film by Luis Fernando Carvalho. For the purposes intended in this study, language is seen in the prediscursive stage in the center of the Borromean knot, the interstitial space of representative circles of the Lacanian triad - the Real, the Symbolic and the Imaginary. Language is also seen as having a

\footnotetext{
* Professora de Comparatismo e Tradução no Mestrado em Letras-Literatura Comparada, na Universidade Regional Integrada do Alto Uruguai e das Missoes-URI, e de Análise de Discurso, na Licenciatura em Letras, na mesma Universidade. Doutora em Letras pela Universidade CatólicadePelotas. E-mail: theve47@gmail.com
} 
borderline nature between the psychic and the somatic, the starting point for two other drives observed by J. Lacan - the invocatory and the scopic ones.

KEYWORDS: Literary language. Filmic language. Body. Senses. Discourse analysis.

[...] ainda confuso, aturdido, mostrei-lhe a cadeira do canto, mas ele nem se mexeu e tirando o lenço do bolso ele disse "abotoe a camisa, André". (Raduan Nassar, pela voz de André, o sujeito discursivo-narrador - SDN - Lavoura arcaica, p. 1112.)

\section{INTRODUÇÃO}

Casa do Real intangível, inalcançável - esse é o corpo em que existimos, o universo em que nos movimentamos e que nos traduz. Como um espelho, ele nos reflete desde o nosso interior, dá-nos visibilidade diante do olhar do outro e, ao mesmo tempo, convive com o Outro que nos habita.

Na constituição psicanalítica da linguagem, de que o corpo é conduto e expressão, encontram-se o Real, o Simbólico e o Imaginário, a tríade que, na teoria lacaniana, demonstra o funcionamento da cadeia significante, tal como exemplificado pelo Nó Borromeano, figura topológica em que esses três registros aparecem representados por três círculos entrelaçados, a demonstrarem também a relação de interdependência que os une.

Neste artigo, a imagem-percepção do corpo é vista como uma linguagem em estado pré-discursivo, no centro do Nó Borromeano. Estando no ponto vazio que Lacan chama de "objeto $\boldsymbol{a}$ ", localizado no espaço intersticial dos três círculos representativos dos registros mencionados, essa imagem/linguagem é recoberta pelo simbólico e pelo imaginário. Ao mesmo tempo, é igualmente revestida pela pulsão na perspectiva relembrada por Freud, de caráter limítrofe entre o psíquico e o somático, condição que permite a vazão de duas outras pulsões, a invocante e a escópica, como adiante se demonstra.

Dito isso, tem-se aqui, como objetos significantes sob considerações analíticas, duas linguagens distintas, mas complementares entre si. São elas a narrativa literária e a fílmica, esta como uma adaptação/tradução da primeira para outro código, o imagético em movimento.

\section{CORPO (EM)DISCURSO, PALAVRA E IMAGENS EM MOVIMENTO}

A versão primeira de Lavoura arcaica, daqui em diante designada simplesmente LA, na condição de narrativa literária, inicia transbordante de sentidos. André, personagem narrador, para efeitos deste texto visto como sujeito discursivo-narrador (SDN), observa-se habitante de um corpo latejante, em estado de nudez física, psíquica e sensorial, que se entrega a uma espécie de ascese, de consagração, ou mesmo de tradução, do humano ao divino, tal como é possível depreender-se da leitura do Recorte Discursivo (RD), a seguir, em que o destaque é o quarto, mundo individual que acolhe o corpo, mas também é o corpo, inviolável catedral, que acolhe os sentidos à espera da celebração máxima:

\section{RD 1}

Os olhos no teto, a nudez dentro do quarto; róseo, azul ou violáceo, o quarto é inviolável; o quarto é individual, é um mundo, quarto catedral, onde, nos intervalos da angústia, se colhe, de um áspero caule, na palma da mão, a rosa branca do desespero, pois entre os objetos que o quarto consagra estão primeiro os objetos do corpo; eu estava deitado no assoalho do meu quarto, numa velha pensão interiorana [...] (NASSAR, 1989, p. 9.)

O olhar voltado para o alto, para o teto do quarto, leva o leitor a deduzir que o SDN está deitado de costas. Sua percepção do entorno, pela posição em decúbito dorsal em que se encontra, permite ao SDN experimentar a sensação de que tudo a sua volta se 
torna fluido, misturando-se para explodir depois, pelo encontro simbiótico entre desejo latente e desejo satisfeito. O rosa e o azul, cores que ele sensorialmente percebe se tornando um todo violáceo, simbolizam a um só tempo o desejo que, à moda de uma chispa, alastra-se na procura de satisfazer-se e, também, a sensação de calma obtida após a satisfação dos sentidos.

A propósito, vem da psicanálise a noção de que não se pode explicar um acontecimento sensorial sem que seja registrado sob a forma de uma representação. Essa representação, psíquica ou não, é identificada por Nasio (2009) como imagem mental do corpo. Segundo ele, "[...] toda sensação percebida imprime inevitavelmente sua imagem; toda sensação real é necessariamente duplicada por uma virtualidade [...] O corpo é também uma cosa mentale" (p. 08), afirma ele ao lembrar Da Vinci, que qualificava a pintura como cosa mentale "porque a pintura - pensava ele - não está na tela, mas na cabeça daquele que a pinta ou do espectador que a contempla”, completa Nasio (2009, p. 08).

Em que condição, no entanto, trazem-se aqui estas considerações a respeito da imagem do corpo como morada do Real, do Simbólico e do Imaginário, e, ao mesmo tempo, destes sendo conduto e expressão daquele? A resposta é que, sendo este trabalho baseado numa visão discursivo-comparatista e tendo por base primeira uma obra literária, é necessário ver a imagem por esta criada como resultante de um processo de literalização, sim, mas igualmente de socialização. Ora, não há socialização dissociada da ideologia e tampouco do imaginário. Nessa perspectiva, conforme salienta Pageaux (2011, p. 110-111), é possível afirmar que

\footnotetext{
A ideologia e o imaginário constituem, de maneira significativa, os dois polos antagônicos e complementares de um estudo de imagologia 1. Segundo as temáticas abordadas, ora a preferência será dada à ideologia (e o estudo da imagem virá em contribuição àquilo que podemos continuar chamando de história das ideias), ora ela vai se orientar em direção à poética (principalmente quando for o caso de estudar a forma e a prática literária de um escritor ou de um conjunto de textos), mas também em direção ao imaginário (aquele do escritor, da época, ou de seu meio, de sua escola). Trata-se de um equilíbrio a construir ou a encontrar, em função da temática escolhida [...]. A imagem é uma espécie de língua, de língua segunda para dizer o Outro e, consequentemente, para dizer também um pouco de si, de sua cultura.
}

Daí, portanto, entender-se o "parentesco" linguisticamente possível entre a imagem mental sugerida ao leitor pela interação dialógica que mantém com o discurso literário que lê a partir da obra impressa, no caso o romance LA, e a imagem que lhe chega como uma narrativa discursivo-fílmica, esta legível no filme homônimo ao romance de Nassar. Nesta, as imagens chegam aos olhos do espectador-leitor filtradas pelo olhar analítico-interpretativo do diretor cinematográfico.

A relação entre a palavra escrita/lida e a imagem vista/ouvida guarda, todavia, uma palavra/imagem que, mesmo lida no código escrito ou no fílmico-imagético, inexiste. Nem dita e tampouco ouvida ou vista, ela habita o antes do começo. Inominada ainda, em estado anterior a si própria, ela é constituinte do sujeito-narrador-leitor ou espectador na forma de um silêncio que a identifica como ainda estando na condição de "objeto $\boldsymbol{a}$ ". Há um silêncio que ultrapassa todo o dizer, como lembra Carnevale (2015, p. 68): "A constituição dos sujeitos se dá não apenas via significantes ofertados pelo Outro, mas, também, via silêncio [...] Somos constituídos no silêncio que ultrapassa todo dizer [...]”. Depreende-se dessa realidade uma outra - há interstícios por onde vaza esse silêncio para transmudar-se em palavra, palavra falada ou palavra escrita, palavra hibridando-se com a imagem, mas sempre palavra incompleta, palavra opaca, fenda por onde vaza o inconsciente.

No RD 2, a seguir, apresentam-se pistas desse silêncio primordial, fundante de todo ser de linguagem. Há também um movimento de alternância de tempo e de sentidos nos discursos dos dois irmãos. Observe-se:

\section{RD 2}

Era meu irmão mais velho que estava na porta; assim que ele entrou, ficamos de frente um para o outro, nossos olhos parados, era um pedaço de terra seca que nos separava, tinha susto e espanto nesse pó, mas não era uma descoberta, nem sei o que era, e não nos dizíamos nada, até que ele estendeu os braços e fechou em silêncio as mãos fortes nos meus ombros e nós nos olhamos e num momento preciso

\footnotetext{
${ }^{1}$ Imagologia, primeira vertente derivativa da Literatura Comparada, cf. Celeste H. M. Ribeiro de Souza.
} 
nossas memórias nos assaltaram os olhos em atropelo, e eu de repente vi seus olhos se molharem, e foi então que seus olhos se molharam, e foi então que ele me abraçou, e eu senti nos seus braços o peso dos braços encharcados da família inteira. Voltamos a nos olhar e eu disse "não te esperava" foi o que eu disse com o desajeito do que dizia e cheio de receio de me deixar escapar não importava com o que eu fosse lá dizer, mesmo assim eu repeti "não te esperava" foi isso o que eu disse mais uma vez e eu senti a força poderosa da família desabando sobre mim como um aguaceiro pesado enquanto ele dizia "nós te amamos muito, nós te amamos muito" e era tudo o que ele dizia enquanto me abraçava mais uma vez [...] (NASSAR, 1989, p. 11)

Há, nesse RD, pistas complementares que conduzem o leitor à percepção do silêncio como um furo, um buraco inacessível, poço ao fundo do qual é impossível o acesso do sujeito na sua incessante luta pela completude. Analisem-se, por exemplo, nos seguintes RD 2a e RD 2b:

RD 2a - Era meu irmão mais velho que estava na porta. (NASSAR, 1989, p. 11).

É perceptível que se está diante de uma proposição inteiramente ambientada no tempo pretérito, o tempo da memória. O SDN, ao abrir a porta, vê quem bate, mas não individualiza esse alguém pelo nome. Ao contrário disso, a explicação que dá, meu irmão mais velho, recupera a gênese familiar pelo vínculo de pertencimento afetivo, traduzido pelo pronome pessoal meu, numa escala de tempo que, ao avançar, retroage ao começo, ou melhor, ao antes do começo, no âmbito do objeto $\boldsymbol{a}$. Como afirma Pêcheux (2008, p. 23), a explicação dada pelo SDN faz imergir

[...] esse enunciado em uma rede de relações associativas implícitas- paráfrases, implicações, comentários, alusões, etc. - isto é, em uma série heterogênea de enunciados, funcionando sob diferentes sistemas discursivos, e com uma estabilidade móvel variada.

Dessa forma, ao afirmar que era seu irmão mais velho, o SDN recupera um discurso de resistência do eu, eis que insere não uma, mas várias gerações produtoras de um discurso que remete à sua formação discursiva de pertencimento. As sequências imediatamente posteriores - era um pedaço de terra seca que nos separava, tinha susto e espanto nesse pó, mas não era uma descoberta, nem sei o que era, e não nos dizíamos nada - são reiterativas do discurso de resistência desse eu. Têm a ver ao mesmo tempo com o interdiscurso "da ordem do ex-cêntrico, isto é, daquilo que se situa fora do que está sendo dito, mas que incide na cadeia significante, marcando uma desordem no enunciado", como afirma Ernst (2009, p. 5), ao se referir ao estranhamento como estratégia discursiva "que expõe o conflito entre formações discursivas [...]", estranhamento esse cujas pistas afloram na superfície discursiva, como em “[...] tinha susto e espanto nesse pó, mas não era uma descoberta, nem sei o que era [...].” (NASSAR, 1989, p. 11).

No RD destacado, novamente há um silêncio em que se gesta uma palavra não-dita, que recobre o inalcançável - a falta, marca indelével, permanente, do humano. Há um excesso de significantes de um mesmo silêncio, como a secura da terra e seu efeito de véu, cortina de isolamento entre os múltiplos sentidos de um mesmo discurso, ou ainda, o estranhamento causado por uma volta que assusta, eis que se assemelha a um inusitado que, no entanto, é já conhecido de antes - o já-lá - já dito, já-vivido, e que parece retornar, ou que espanta pelo novo que provoca, ou pelo que parece novo sem sê-lo. É voz que fala pelo gesto do corpo, é o inconsciente que toma a palavra e se apresenta, é ele que diz e se diz e, ao dizê-lo, faz-se sujeito, dá e faz sentido.

$\mathrm{RD} 2 \mathrm{~b}-[. .$.$] até que ele estendeu os braços e fechou em silêncio as mãos fortes nos meus ombros e$ nós nos olhamos e num momento preciso nossas memórias nos assaltaram os olhos em atropelo, e eu vi de repente seus olhos se molharem (NASSAR, 1989, p. 11.)

Nesse RD, o SDN transpõe a barreira de si mesmo pelo olhar do outro que o atravessa e, nessa travessia, transborda. É nesse transbordamento que o olhar do irmão, em LA, produz sentido para ele, sujeito discursivo-narrador. Seus olhos se molharam, fala o SDN, vendo confluir na superfície do rosto molhado do irmão não somente uma imagem, mas várias que nela se 
consubstanciaram e agora vazam, transbordantes. Estão à tona no abraço que une os dois irmãos, tanto quanto pelo excesso contido no discurso, reiterado uso repetido da aditiva e (... e fechou em silêncio... e nós nos olhamos... e num momento preciso... e eu vi de repente...), por exemplo.

Dito de outra maneira, em se tratando de palavras que geram imagens, tanto a palavra pode ser a mesma, mas geradora de outra imagem semantizada, tanto quanto a imagem nunca é uma imagem somente. Assemelhando-se a uma fotografia enclausurada numa moldura da qual foram descartadas as sobras laterais, como já explicou Castillo (2015), toda imagem é também as outras que ela não mostra, aquelas que a sustentam e as seguintes que lhe asseguram continuidade semântico-temporal no contexto discursivo.

Não há, pois, um sentido único na imagem. Sendo plural, ela é tempo excedente; pode ainda ser um instante fora do tempo em que ela mesma é produzida, um tempo recortado, que se aparta de um tempo anteriormente marcado na linha espaço-temporal do próprio SDN, como se destaca no discurso da rememoração [...] num momento preciso nossas memórias nos assaltaram [...]. A imagem é, assim, tempo imagístico retido e guardado em determinado espaço de memória do SDN, mas é também tempo em movimento, na medida em que, instado pela exterioridade que o constitui e interpela, é um tempo em constante fluir/refluir.

O fluir antes mencionado fica mais evidente quando se observa o movimento pendular presente nas notações inculcadas no discurso de SDN pelo uso da pronominalização, como se depreende do uso alternado de eu e nós, perceptível no RD 2. Observa-se nitidamente a presença de um espaço semântico pertencente ao SDN André e outro pertencente a Pedro, o irmão que chegara trazendo em si uma espécie de relembrança de que o um só é um pelo vínculo com o um dos outros transformados em um nós.

A chegada de Pedro contrasta o individual que se desgarrara com o coletivo que a sua presença traz à superfície discursiva. Essa presença inesperada coloca no agora um pertencimento simbolicamente irrevogável, qual seja, a presença da própria voz como afirmação de identidade, juntando-a à voz coletiva da família anunciando-se pluralizada - nós te amamos, nós te amamos. Reiterada está, assim, a permanência da união entre o um (SDN) e os outros (o irmão, Pedro, e os demais da família) pelo uso do verbo amar, com sentido pleno, transformado em ação que prescinde de definição espaço-temporal justamente porque transcendeu a esses dois indicadores semânticos, como se verá logo adiante.

Leem-se nesse discurso do reencontro dos dois irmãos três outros discursos - o da falta, subjacente na expressão "eu não te esperava" e que vem à tona com a presença do visitante inesperado, podendo significar surpresa, mas também desejo de continuar sendo um eu necessitado de assim permanecer; o discurso do excesso traduzindo-se na reiteração do discurso apelativo "nós te amamos, nós te amamos", e o discurso do estranhamento frente ao inesperado que se desenrola diante do SDN e o envolve à sua revelia, como se o estivesse colocando, sob cadeados, numa jaula da qual não poderia escapar outra vez: $o$ que eu disse com o desajeito do que dizia e cheio de receio de me deixar escapar não importava com o que eu fosse lá dizer, mesmo assim eu repeti "não te esperava". Nesta sequência se evidenciam os três conceitos-chave - quais sejam, a falta, o excesso e o estranhamento - que, na condição de conceitos gerais e não como dispositivos técnicos (ERNST, 2009, p. 2) pontuam o trabalho do analista ao tratar com o corpus discursivo. Contextualizem-se discursivamente três expressões presentes na materialidade discursiva em análise. A primeira é a constatação sobre o desajeitamento, o estar pouco à vontade para viver aquela realidade discursiva que inopinadamente a presença do irmão o fez vivenciar (o que eu disse com o desajeito do que dizia), justamente quando vivia a sensação de plenitude que lhe chegara pelo sexo, gozado à capela. A segunda expressão não apenas reafirma o valor semântico da primeira como a realimenta ainda mais (cheio de receio de me deixar escapar não importava com o que eu fosse lá dizer), enquanto a terceira ressalta a opacidade semântica presente em não te esperava. Seria essa opacidade semântica uma realidade-enigma, impossível de traduzir-se com clareza por situar-se num meio-caminho, num espaço intervalar entre a materialidade discursiva (do intradiscurso) e a memória discursiva (o interdiscurso), numa reiteração de surpresa ou de quase rechaço à presença inesperada que lhe turvara o prazer quase terapêutico para um corpo macerado pelo desejo?

Forum linguistic., Florianópolis, v.14, número especial, p.2492-2500, nov.2017. 


\section{CORPO EM DISCURSO: MOVIMENTO 1 - VOLTANDO AO INÍCIO}

A cena introdutória de Luís Fernando Carvalho, o diretor da tradução de Lavoura Arcaica da linguagem literária impressa para a linguagem fílmica homóloga, recupera em segundos a corrida de um menino, que se verá depois ser André, o SDN do romance de Nassar. O personagem corre por um caminho margeado, à sua direita, pela encosta de um vale e, pela esquerda, por uma fileira de árvores que acompanham uma cerca de arame. Da direita para a esquerda da tela, o menino corre, braços abertos, rosto alegre e cabelos em desalinho, tocados pelo vento.

Repentinamente, o olho da câmera se amplia. O menino está, agora, a poucos passos do fim do caminho estreito marcado pela cerca de arame. O espectador é conduzido, pelo olhar da criança, até o fundo do vale. Lá embaixo, à esquerda, o que o espectador vislumbra é feito um flash sobre uma moradia cercada por tufos verdes, árvores que à distância parecem arbustos.

Corte.

Na sequência, em primeiro plano, vê-se o menino de costas, ainda correndo, mas em direção a uma porta sem marcos, vazada na parede, com a parte superior recortada em forma de abóbada, abrindo-se para um pátio interno, translúcido pela imagem clara de um dia tecido de azul harmonizando-se com o dourado solar. Ato contínuo, a corrida cessa. O menino abre os braços, inclina o corpo e se joga desde a soleira da porta.

O olho humano do diretor ultrapassa o visor da câmera, olho artificial, cúmplice de um outro olho, atento e curioso, o do espectador ante o que lhe sugere o gesto do personagem. Ao encontro de quê ou de quem correu a criança e onde se jogou são perguntas aparentemente tão lógicas quanto presumíveis seriam as respostas. O pequeno André mergulhou no vazio do espaço, ao encontro de si mesmo, do Outro, talvez?

Tempo/instante decorrido. Nada do presumido aconteceu. Diante do olhar voyeurista da plateia, a revelação se escancara. Ouvese uma risada espontaneamente infantil. Vem acompanhada do ruído de algo pesado sobre uma superfície que abafa o barulho da queda. O personagem voara ao encontro de nada mais, nada menos, do que um monte de palhas - capim seco, à espera de saciar a fome de algum bovino, ou de acolchoar a noite de algum notívago contumaz, eis o que a câmera, pelo olho do diretor, informa à plateia.

Feita está a passagem. A aterrissagem do corpo jovem e lépido sobre a palha macia acontece acompanhada pelo riso aberto do personagem, espécie de louvação à liberdade de, se cair, levantar e prosseguir.

\section{CORPO EM DISCURSO: MOVIMENTO FINAL, O USUFRUTO DO PRAZER...}

Lavoura Arcaica (2001) o filme propriamente dito, começa com os créditos iniciais surgindo sobre a imagem de uma folha de plátano, já ressequida pelo clima de outono. Tomada em primeiro plano, a imagem da folha relembra uma pele envelhecida, de tons amarronzados que deixam perceber sulcos bem definidos, nervuras salientes em um rosto de terra crestada feito. Eis o tempo, eis o rosto, eis a terra da e para a qual foi feito esse rosto, esse corpo.

Adiante-se. O tempo aqui é o tempo da memória inscrita em práticas, como refere Pêcheux (1999, p. 50), que se historiciza em outra linguagem, a fílmica. Esta chega ao espectador estruturada a partir da infância do personagem, readquirindo vida pela imagem de um menino feliz, correndo livre, vivendo um tempo todo seu, sem datas marcadas. Depois, é assinalada pela ruptura gradativa entre um tempo passado, tempo de memória - recuperado simbolicamente pela imagem da folha de plátano que já perdera seu viço - e outro, ampliando-se num tempo presente, durativo. Este irá desenovelando-se aos poucos, do frêmito inicial encapsulado entre quatro paredes, no silêncio cúmplice do quarto quase lúgubre, silencioso e modorrento cúmplice da pulsão sexual que transporta o personagem do abismo ao paraíso da libido satisfeita. 
O tempo agora é outro. Ele é, agora, o tempo da imagem - da imagem-palavra não dita, mas presente, fazendo-se discurso em movimento, movimento corpóreo, caudatário das emoções dos personagens de uma narrativa verbal traduzida para a linguagem fílmica.

Ora, a cena com que Luís Fernando Carvalho escolhe começar a narrar LA na perspectiva da narrativa fílmica recupera uma noção antiga - a de que o orgasmo levado ao seu ápice conduz o indivíduo a sentir-se em um tal nível de gozo que alcançaria a sensação de um prazer absoluto e inenarrável, semelhante, talvez, a uma quase morte.

É um pouco isso o que sugere a câmera do diretor na transposição fílmica da cena inicial do romance de Nassar. A cenografia criada por Carvalho é fiel à proposta do romancista. O quarto é quase franciscano. O piso é de madeira, a cama é simples, as paredes são nuas. A mais, somente a sombra esvoaçante de uma cortina em dois panos, tecido rendado por onde a luz do dia se infiltra e faz arabescos na parede. Além da cortina, apenas uma lâmpada apagada, presa ao teto por um suporte semelhante ao rodado de uma carroça, que mais parece uma aranha escura balançando-se no ar.

Esse é o quarto-casulo em que André é uma presença física ainda ausente para o espectador. Abrigar-se nesse quarto é fugir do convívio social que, na narrativa de Nassar, é representada pela família do personagem. É nesse espaço discursivo que a cena fundadora da narrativa fílmica se estabelece. O espectador vislumbra, no ambiente à meia-luz, uma imagem que pode lembrar ondas em movimento sob o luar. O claro da superfície alternando-se com o escuro em movimento sincronizado com o som de uma locomotiva que avança.

Na medida em que aumenta o som vindo de fora, avança o movimento da câmera sobre a superfície em movimento. Aos poucos, o espectador começa a perceber que aquele ir e vir de luz e sombra é uma coberta, um lençol, talvez. Avança o som da locomotiva e avança o olho da câmera sobre a superfície em movimento.

Diante do olhar do espectador, há um corpo masculino que se excita, no afã de alcançar um mais-gozar que "pode ser visto como circulando 'fora' do sujeito, no Outro”, como explica Fink (1998, p. 123). Esse corpo, na cena transcrita para a linguagem fílmica, é simultaneamente um objeto de desejo e um objeto que causa desejo, conforme lembra o mesmo autor.

É oportuno, aqui, lembrar o mesmo Fink (1998, p. 82-83) recordando a comparação entre o conceito marxista de mais-valia - os juros, o lucro, que o capitalista toma para si ao invés de dividi-lo com os empregados - e o conceito de objeto $\boldsymbol{a}$, "[...] resto produzido pelo rompimento da unidade hipotética mãe-criança devido à própria natureza do desejo”, revelado como a causa do desejo do Outro, na perspectiva lacaniana. Pelo viés psicanalítico, o capitalista representaria o Outro, para quem o sujeito trabalharia e se sacrificaria pelo seu gozo.

Portanto, na cena que se descortina na tela, há um sujeito dividido, clivado desse resto, buscando sua completude, quiçá imaginando tê-la alcançado graças à ilusão da totalidade, como explica Fink (1988, p. 83):

Ao clivar-se desse resto, o sujeito dividido, embora excluído do Outro, pode sustentar a ilusão da totalidade; ao apegar-se ao objeto a, o sujeito é capaz de ignorar sua divisão. [...] É na relação complexa do sujeito com o objeto a [...] que o sujeito obtém uma relação fantasmática de completude, preenchimento, satisfação e bemestar.

A batida à porta, repetidas vezes, quebra essa relação fantasmática de completude, preenchimento, satisfação e bem-estar buscada pelo SDN. Rompe-se a cena. O corpo desfaz uma unidade por poucos minutos alcançada - a do gesto fazendo-se palavra/discurso do corpo, eis que - como lembra Iannini (2016, p. 35) - o corpo só fala, realmente, quando alguma coisa claudica. Nesse instante, em que uma mão fechada se choca em ritmo acelerado contra a porta do quarto-casulo, o que claudica - porque inicia a se decompor - é a fantasia do preenchimento do buraco vazio, morada do desejo sempre incompleto, do interstício em que se aloja como o objeto $a$, entre o Real, o Simbólico e o Imaginário. 


\section{5 ... E A CONCLUSÃO - A (DE)COMPOSIÇÃO DA FANTASIA}

André levanta-se. A câmera desfaz o ilusório. O leito em que o prazer fora alcançado não era o talvez imaginado pela plateia, mas sim o chão de madeira, material que desde tempos remotos em algumas civilizações tem sido consagrado às divindades, simbolizando também a morada de Deus.

O SDN levanta primeiro a calça, depois veste a camisa e se dirige à porta. Ao abri-la, percebe-se descoberto em seu exílio voluntário. Do outro lado da soleira, um personagem masculino o encara. É Pedro, o irmão. Segundos de silêncio e imobilidade entre os dois. Os olhares de ambos se encontram e se transformam em um só. André rompe o silêncio. Eu não te esperava... Pedro não responde. Eu não te esperava... A voz de André repete pela segunda vez o que já é quase um mantra. A resposta de Pedro também é reiterativa do sentimento familiar de que se diz tradutor e portador, da identidade discursiva que os une: Nós te amamos muito... Nós te amamos muito... Um abraço reaproxima os dois irmãos até que o visitante rompa definitivamente com o estado quase letárgico, de prazer e gozo, que mantivera André imerso na fantasia de estar manipulando sua relação com o objeto $\boldsymbol{a}$, satisfazendo o desejo do Outro: Abotoe a camisa, André.

Querendo ou não, o assujeitamento do SDN à sua formação discursiva familiar está reafirmado por essa voz. O SDN André, submetido à ordem da ideologia e do inconsciente, tendo reestruturada outra vez, no discurso imperativo-coercitivo de Pedro, o irmão, a memória estruturante do seu dizer, volta a ser o que nunca deixara de ser - um sujeito clivado, dividido - em constante luta com a própria substância, o dentro e o fora do próprio corpo, a fantasia do desejo e do mais-gozar.

Portanto, ao se proceder à análise de um discurso que se manifesta em duas linguagens diferentes, embora complementares, como a literária e a fílmica, como em LA, buscou-se evidenciar que as várias formas do dizer e do não-dizer, na perspectiva dos três conceitos-chave mencionados por Ernst (2009, p. 2) - da falta, do estranhamento e do excesso - constituem-se dispositivos indispensáveis à prática interpretativa. Eis que o intuito não é o de se analisar o dito ou o mostrado como referência, mas o de revelar o mecanismo da representação mesma, na interação das duas linguagens como materialidades discursivas portadoras e criadoras de sentidos que tornam evidente a pertinência da intertextualidade existente entre eles.

\section{REFERENCIAS}

LAVOURA ARCAICA. Dir. Luís Fernando Carvalho. [Filme, baseado na obra homônima de Raduan Nassar]. 172 min. Colorido. NTSC. Dolby Digital 2.0 e 5.1. Distribuição: Europa Filmes,

2001.

CASTILLO, Alejandra. Imagen, cuerpo. Adrogue - Buenos Aires, RA: La cebra, 2015.

ERNST, A. G. A falta, o excesso e o estranhamento na constituição/interpretação do corpus discursivo. In: SEMINÁRIO DE ESTUdOS EM ANÁLISE DO DISCURSO, 4., 2009, Porto Alegre, RS. Anais... Porto Alegre: UFRGS, 2009. Disponível em: $<$ http://anaisdosead.com.br/4SEAD/SIMPOSIOS/AracyErnstPereira.pdf>. Acesso em 10 mai. 2016.

FINK, Bruce. O sujeito lacaniano; entre a linguagem e o gozo. Trad. de Maria de Lourdes Duarte Sette. Rio de Janeiro: Zahar, 1998.

IANNINI, Gilson. Prelúdio. In: Revista Cult, n. 211, p. 35, abr. 2016.

NASIO, J-D. Meu corpo e suas imagens. Trad. André Telles. Rio de Janeiro: Zahar, 2009.

NASSAR, Raduan. Lavoura arcaica. São Paulo: Companhia das Letras, 1989. 
PAGEAUX, Daniel-Henri. Musas na encruzilhada: ensaios de literatura comparada. In: MARINHO, Marcelo; SILVA, Denise Almeida; UMBACH, Rosani Ketcher (Orgs.). Frederico Westphalen/RS: URI; São Paulo, SP: Hucitec; Santa Maria, RS: UFSM, 2011. p. 109-127.

PÊCHEUX, Michel. O discurso: estrutura ou acontecimento. Trad. Eni P. Orlandi. Campinas, SP: Pontes, 2008.

. Papel da memória. In: ACHARD et al. Papel da memória. Trad. e Intr. de José Horta Nunes. Campinas, SP: Pontes, 1999. p. 49-56.

SOUSA, Celeste H. M. de. R. Literatura e imagologia: uma interação produtiva. A contribuição comparatística da Universidade de Aachen. Pandemonium. São Paulo, n. $17,2011 . \quad$ Disponível em: <http://www.fflch.usp.br/dlm/alemao/pandemoniumgermanicum> Acesso em: 24 jul. 2016. 